\title{
Especies nuevas de Lonchocarpus (Millettieae: Leguminosae) para Costa Rica y Panamá; lectotipificación de la sect. Densiflori Benth.
}

\author{
New species of Lonchocarpus (Millettieae: Leguminosae) from Costa Rica and Panama; \\ lectotypification of sect. Densiflori Benth.
}

\author{
Mario Sousa S. \\ Herbario Nacional, Instituto de Biología, UNAM, Apartado postal 70-367, 04510 México, D.F. México \\ Correspondencia: sousa@ibiología.unam.mx
}

\begin{abstract}
Resumen: Se describen e ilustran cuatro especies de Lonchocarpus (Millettieae, Papilionoideae), L. haberi, L. latisiliquus, $L$. megacarpus y L. monteviridis, dos endémicas de Costa Rica, una de Panamá y la otra habita en ambos países. De las especies nuevas, tres pertenecen a la sect. Densiflori Benth., a la cual se le lectotipifica aquí, y se elaboró una clave de esta sección para Costa Rica y Panamá.
\end{abstract}

Palabras clave: Leguminosae, Lonchocarpus, Costa Rica, Panamá.

\begin{abstract}
Four new species of Lonchocarpus (Millettieae, Papilionoideae), L. haberi, L. latisiliquus, L. megacarpus and L. monteviridis, are described and illustrated; two are endemic to Costa Rica, one to Panama and one is found in both countries. Of these new species, three belong to sect. Densiflori Benth., which is herein lectotypified; a key to the section for Costa Rica and Panama is provided.
\end{abstract}

Key words: Leguminosae, Lonchocarpus, Costa Rica, Panama.

\section{Introducción}

Como parte de la elaboración del tratamiento del género Lonchocarpus (Millettieae, Papilionoideae) para la Flora Mesoamericana, se describen nuevas especies para Costa Rica y Panamá, anteriormente ya se describieron para esta región Lonchocarpus ferrugineus M. Sousa (1987), L. hughesii M. Sousa (1992), y L. chiangii M. Sousa (2000). Con estas adiciones ya suman 29 especies de Lonchocarpus conocidas para Costa Rica y 21 especies para Panamá. Para Mesoamérica, la entidad con mayor número de especies de Lonchocarpus es Chiapas, México, con 36 especies seguida de Honduras con 33.

Lonchocarpus haberi M. Sousa, sp. nov. Tipo: COSTA RICA. Puntarenas. San Luis Valley, elev. 1100-1200 m, 29 septiembre 1985. W.H. Haber y E. Bello C. 2939 (holotipo, MEXU; isotipos, MEXU, MO). Fig. 1.

Arbor 6-15 m alta; folia (1-)3(5)-foliolata, foliolis ellipticis vel late ellipticis, interdum ovatis vel late ovatis, apice acuminatis. Inflorescentiae erectae, $2.5-7 \mathrm{~cm}$ longae, pedunculis floralibus $3.5-5 \mathrm{~mm}$ longis, pedicellis 3.5-4.5 $\mathrm{mm}$ longis. Legumen indehiscens, latum, coriaceum vel

Recibido: 05 julio 2004; aceptado: 18 mayo 2005 subcoriaceum, dense vel moderate griseo-luteo-velutinum, seminibus 1-2(-4), late reniformibus.

Árboles 6-15 m de alto; corteza gris, exfoliando en placas, sin fluido resinoso al corte; ramas sólidas, cuando jóvenes esparcidamente canescente seríceas, pronto glabras. Hojas (1-) 3 (-5)-folioladas, folíolos elípticos a anchamente elípticos, en ocasiones ovados a anchamente ovados (2.5-) 4.5-7 (-9) cm de largo, (1.5-) 2.9-5 (-6) cm de ancho, cartáceos a subcoriáceos, las áreas internervias algo translúcidas, esparcidamente canescente seríceos, pronto glabros en el haz, densa a moderadamente canescente seríceos en el envés, pronto glabrescentes, el ápice acuminado rara vez caudado, nervaduras primaria y secundarias ligeramente realzadas en el envés, nervaduras laterales 8-12; estípulas pronto caducas, no vistas. Inflorescencias simples, erectas, $2.5-7 \mathrm{~cm}$ de largo; pedúnculos florales espaciados, delgados, 3.5-5 $\mathrm{mm}$ de largo, bráctea subyacente, ovada a elíptica, cóncava 0.4-0.5 mm de largo; pedicelos 3.5- $4.5 \mathrm{~mm}$ de largo, bractéolas desconocidas; flores desconocidas. Legumbre indehiscente, elíptica a oblonga, 5-7.2 (-12.5) cm de largo, 1.9-2.4 (-3) cm de ancho, la base y ápice atenuados a largamente atenuados, algo constricta entre las semillas, coriácea a subleñosa, densa a moderadamente pardo-amarillento velutina, el margen vexilar angostamente marginado, hasta $0.8 \mathrm{~mm}$ de ancho, el 


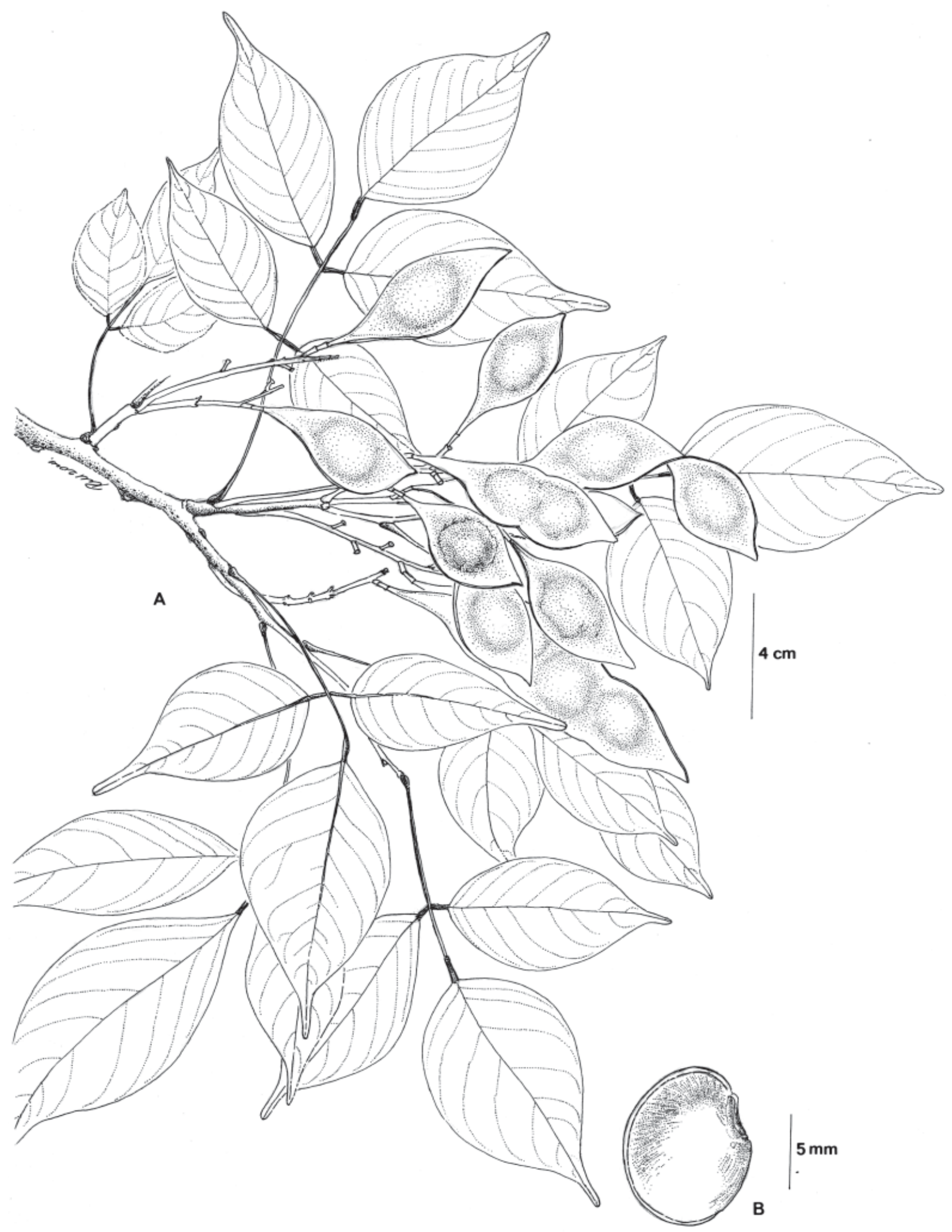

Figura.1. Lonchocarpus haberi M. Sousa. A, rama con hojas e infrutescencias; B, semilla. La rama y semilla fueron tomadas de W. Haber y E. Bello 2939. 
margen carinal angostamente aquillado; semillas 1-2 (-4) por fruto, 9.5-10 mm de largo, 7.5-8 $\mathrm{mm}$ de ancho, 3-3.2 $\mathrm{mm}$ de grueso, anchamente reniformes, color castaño oscuro.

Distribución y hábitat. Endémica de Costa Rica, y sólo conocida en la Cordillera de Tilarán, en los alrededores de la Reserva de Monteverde. Según Haber (com. pers.) su hábitat es en suelos bien drenados y rocosos en los bosques tropicales húmedos premontanos hasta bosques muy húmedos premontanos, en altitudes entre los 600-1200 m. Florece según Haber (com. pers.), de marzo a mayo; fructifica de finales de agosto a mediados de noviembre.

Paratipos. COSTA RICA. Puntarenas: San Luis Village, elev. 800 m, W.A. Haber y E. Bello C. 1627 (MEXU, MO); Valle de San Luis, Monteverde, elev. 1000 m, Haber, Bello y G. Bello C. 2572 (MEXU); San Luis Valley, elev. 1100-1200 m, Haber y Bello 2957 (MEXu); Monteverde, upper San Luis, Pacific slope mont forest, $10^{\circ} 18^{\prime} \mathrm{N}, 84^{\circ} 48^{\prime} \mathrm{O}$, elev. 1000 m, Haber y Bello 6305 (MEXu); 0.5 km below turnoff to San Luis on road to Monteverde-Santa Elena, $10^{\circ} 17^{\prime} \mathrm{N}, 84^{\circ} 51^{\prime}$ O, elev. 1200 m, B. Hammel, M. Grayum y J. Trainer.13772 (MEXU).

\section{Discusión}

Esta especie se relaciona con Lonchocarpus sanctuari Standl. et L.O. Williams, L. chiangii M. Sousa, L. oliganthus F.J. Herm., difiere de las tres porque Lonchocarpus haberi cuenta con hojas preponderantemente 3-folioladas, mientras que las otras cuentan con un mayor número de folíolos. Lonchocarpus haberi tiene frutos 1.9-2.4(-3) cm de ancho, coriáceos a subleñosos y $L$. sanctuari y $L$. changii $0.8-1.6 \mathrm{~cm}$ de ancho, membranáceos a coriáceos. Lonchocarpus haberi cuenta con pedúnculos 3.5-5 mm de largo y pedicelos 3.5-4.5 mm de largo, mientras que L. oliganthus, pedúnculos 1-1.5 mm de largo y pedicelos (0.5-)1.5-2(-3) mm de largo.

Se dedica esta especie al Dr. William A. Haber (1946-), entomólogo norteamericano de Wisconsin, quien ha sido un estudioso de la Flora de la Reserva de Monteverde, C.R., área donde él y sus colaboradores han recolectado más de 17000 ejemplares de una flora de un poco más de 3000 especies de plantas vasculares. El Dr. Haber es casi el único que ha colectado esta especie, así como otras dos nuevas de la misma región.

Lonchocarpus latisiliquus M. Sousa, sp. nov. Tipo: PANAMÁ. Panamá: El Llano-Carti Road, km 17.6, 9 19' N, $78^{\circ} 55^{\prime}$ O, elev. 350 m, G. de Nevers y H. Herrera 3978 (holotipo, MEXU, isotipos, MO y por distribuirse). Fig. 2.

Lonchocarpo pentaphyllo (Poir.) DC. proximus, sed differt statura majore, inflorescentiis longioribus, pedunculis floralibus tenuioribus longioribusque, et leguminibus multo grandioribus, per ventum dispersis.
Árboles 5-30 m de alto; corteza con escaso fluido resinoso al corte; ramas fistulosas, moderada a densamente pardoamarillento seríceas, posteriormente glabrescentes. Hojas 7-9-folioladas, folíolos elípticos a ligeramente obovados en ocasiones (8-) 9.5-10.5(-18) cm de largo, (4-) 5.6-7.5 (-8) $\mathrm{cm}$ de ancho, cartáceos a subcoriáceos, áreas internérvias translúcidas, el haz esparcidamente pardo-amarillento seríceo a glabrescente, el envés moderadamente pardo-amarillento seríceo, el ápice acuminado a caudado, nervaduras primaria y secundarias ligeramente realzadas en el envés, nervaduras laterales 12-15; estípulas caducas, triangulares, ca. $2 \mathrm{~mm}$ de largo. Inflorescencias simples, en ocasiones compuestas, erectas, (5-) 8-15 (-22) cm de largo, flores más o menos esparcidas desde el tercio inferior, floración tardía, pedúnculos florales delgados, 2-3.5 mm de largo, pedicelos 2-2.5 mm de largo, bractéolas alternas, lejanas al cáliz, oblongas a ovadas 0.3-0.5 mm de largo; flores 6-7 mm de largo; cáliz 2$2.5 \mathrm{~mm}$ de largo, epunteado, densamente pardo-amarillento seríceo, ligeramente lobado, el lóbulo carinal 0.2-0.5 mm de largo, anchamente triangular; corola purpúrea, rosada, lila, epunteada, la lámina del estandarte cóncava, suborbicular, 6.5-7 mm de ancho, densamente pardo-amarillento serícea. Ovario 2-4-ovulado. Legumbre indehiscente, elíptica a oblonga, de una semilla 7-13 cm de largo, de 2-3 semillas 9.5-19 cm de largo, 3.5-5.2 cm de ancho, la base y ápice atenuados, cortamente rostrada, recta a algo constricta entre las semillas, coriácea, pardo-amarillento serícea, el margen vexilar sulcado a todo lo largo con 2 bordes laterales, hasta $2 \mathrm{~mm}$ de grosor, margen carinal angostamente aquillado; semillas 1-2 (-3) por fruto, inmaduras.

Distribución y hábitat. Especie conocida de Costa Rica y Panamá. En áreas muy húmedas de selvas altas perennifolias primarias y hábitats riparios. Dentro de sus tallos fístulosos habitan hormigas (véase ejemplar de Jacobs 2178, MO), característica sólo conocida en otras dos especies de Lonchocarpus, L. pentaphyllus (Poir.) DC. y L. spiciflorus Mart. ex Benth. Sus legumbres deben ser dispersadas por el viento (Janzen 136, Mo) y sus semillas muestran daños por insectos (Janzen 136, Mo). La elevación en que vive es entre 100-350 m. La floración parece que se presenta en dos períodos, de mediados de mayo a finales de junio y de mediados de agosto a principios de octubre; fructifica en enero y con un segundo período en septiembre.

Paratipos: COSTA RICA. Heredia: Finca La Selva, the OTS Field Station on the Río Puerto Viejo, E of its junctions with the Río Sarapiquí, elev. 100, I.A. Chacón G. 762 (DUKE); idem, Arboretum, along Quebrada el Sura, M.H Grayum 2328 (MO); Cantón de Sarapiquí, area between Río Sucio and railway tracks, SW Finca Zona Ocho, Río Frío, $10^{\circ} 18^{\prime}$ 00” N, 83 52' 30" O, elev. 110 m, Grayum et al. 8592 (MEXu, Mo); Finca La Selva, the OTS Field Station on the Río Puerto Viejo, E of its junction with the Río Sarapiquí, elev. 100 m, 


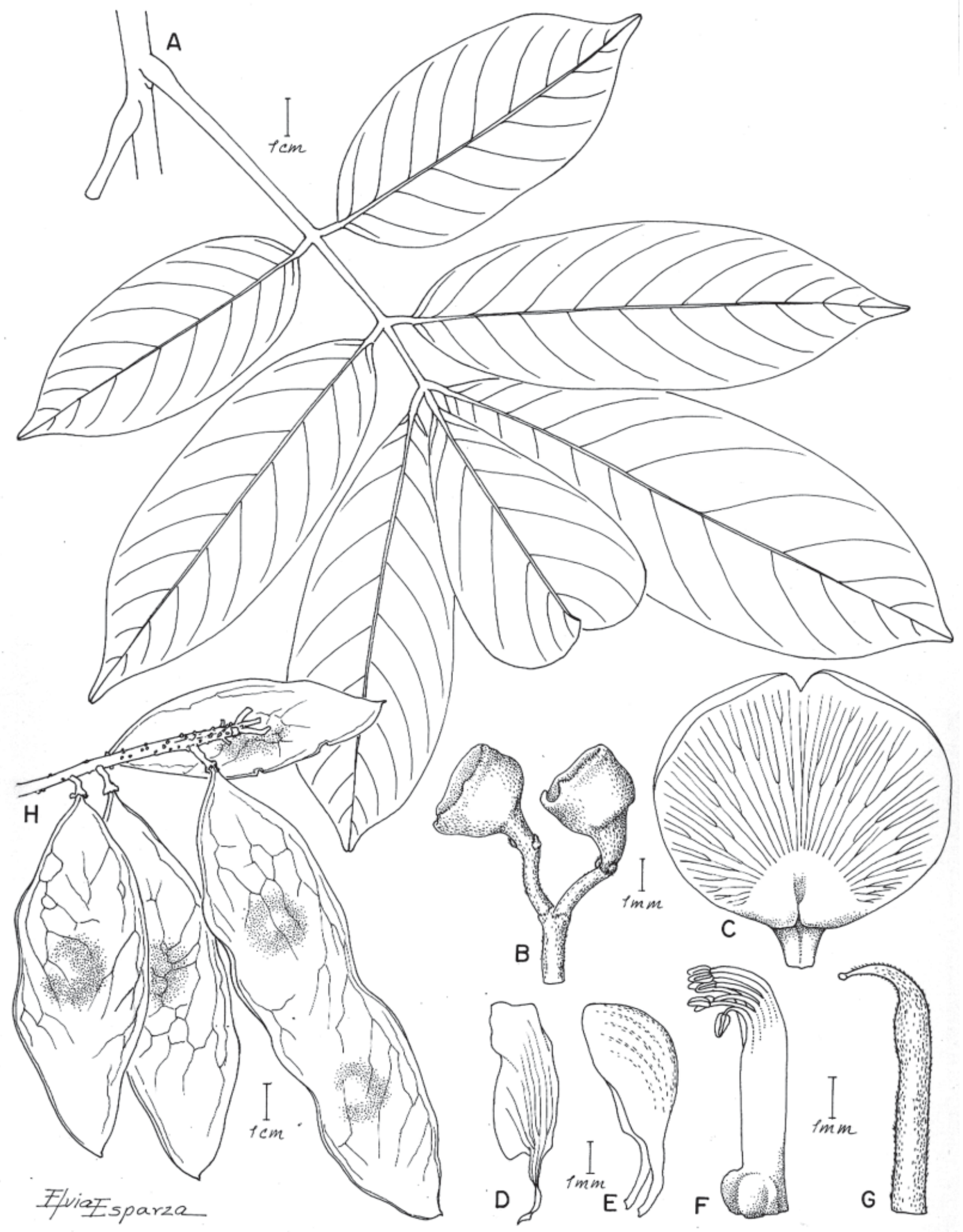

Figura 2. Lonchocarpus latisiliquus M. Sousa. A, hoja; B, unidad biflora, mostrando pédunculo, pedicelos, bractéolas y cálices; C, estandarte; D, ala; E, quilla; F, columna de estambres; G, gineceo; H, infrutescencia. La hoja e infrutescencia fueron tomadas de G. de Nevers y H. Herrera 4541 y la unidad biflora y partes florales de I. Chacón 762. 
B. Hammel 10934 (DUKE); Finca La Selva, Puerto Viejo, Sarapiquí, $10^{\circ} 26^{\prime}$ N, 84 01' O, G.S. Hartshorn 1214 (DUKE, MEXU); idem, B. Jacobs 2178 (DUKE, Mo); Puerto Viejo, Finca la Selva, D. Janzen 136 (Mo); Finca La Selva, in the vicinity of Arboretum along the Quebrada Arboreta about the 900 m line, elev. 100 m, R.L. Wilbur 37251 (DUKE). PANAMÁ. Panamá: Comarca San Blas, Río Nergala, 9 22' N, 79 7 ' O, elev. 100-300 m, de Nevers y H. Herrera 4541 (MEXu, Mo); El Llano-Carti, Rd. 19.1 km from Iteramerican Hwy., $9^{\circ} 19^{\prime} \mathrm{N}, 79^{\circ} 55^{\prime} \mathrm{O}$, elev. $350 \mathrm{~m}$, de Nevers et al. 4849 (MO); El Llano-Cartí Road, 9 16’ N, 78 58' O, elev. 300 m, K.J. Sytsma 998 (MEXU, MO).

\section{Discusión}

Lonchocarpus latisiliquus pertenece a la sect. Densiflori Benth. y está cercanamente emparentada a L. pentaphyllus (Poir.) DC. con quien comparte, entre otras características, el contar con tallos fistulosos y la mirmecofília que acompaña a los ductos que se conectan dentro de ellos. Lonchocarpus latisiliquus difiere de L. pentaphyllus por su mayor porte, árboles hasta de 30, en vez de hasta $15 \mathrm{~m}$ de alto; pedúnculos florales delgados de 2-3.5 mm de largo, en vez de gruesos de $0.8-1.5 \mathrm{~mm}$ de largo; legumbres de $7-19 \mathrm{~cm}$ de largo y $3.5-5.2 \mathrm{~cm}$ de ancho, en vez de 4.5-6.5(-11.5 ) cm de largo y $1.8-2.5 \mathrm{~cm}$ de ancho; con dispersión por viento en vez de por agua.

La etimología del epíteto hace énfasis al ancho de las legumbres.

Lonchocarpus megacarpus M. Sousa, sp. nov. Tipo: PANAMÁ. Colón: Río Guanche, 1-4 km upstream from Portobelo Road, tropical wet forest, elev. 1-100 m, A. Gentry 8805 (holotipo, NY; isotipo, MEXU) Fig. 3.

Arbor 5-15 m alta; folia 11-13-foliolata, foliolis ellipticolanceolatis, apice caudato-subulatis; stipulae linearisubulatae, 1.6-2 mm longae. Inflorescentiae 6.5-8 cm longae, pedunculis floralibus 3-4 mm longis, pedicellis 3-4 mm longis, bracteolis oppositis vel subalternis, a calyce distantibus, ovatis, parvis; flores $10-11 \mathrm{~mm}$ longi, corolla epunctata, vexillo suborbiculari, 8-9 mm lato; ovarium 1-2-ovulatum. Legumen indehiscens, grande, coriaceum vel suberosum, dense griseo-fulvo-velutinosum vel glabrescens, 1-seminale; plantula hypogaea, eophyllis oppositis, unifoliolatis.

Árboles 5-15 m de alto; corteza sin fluido resinoso al corte; ramas sólidas, cuando jóvenes canescente seríceas, pronto glabrescentes. Hojas 11-13-folioladas, folíolos elíptico-lanceolados, (4-) 5.5- 7.5 cm de largo, 1.8-2.4 cm de ancho, cartáceos, áreas internervias translúcidas, glabros en el haz, moderada a esparcidamente seríceos en el envés, el ápice caudado-alesnado, nervaduras primaria y secundarias ligeramente realzadas en el envés, nervaduras laterales 8-
11; estípulas caducas, vistas en plántulas, linear-alesnadas 1.6-2 mm de largo. Inflorescencias simples, $6.5-8 \mathrm{~cm}$ de largo, flores moderadamente espaciadas, floración tardía, pedúnculos florales delgados, 3- $4 \mathrm{~mm}$ de largo, pedicelos 3-4 mm de largo, bractéolas opuestas a subalternas, distantes al cáliz, en el tercio superior del pedicelo, ovadas, 0.3-0.4 mm de largo; flores 10-11 mm de largo; cáliz casi trunco o ligeramente lobado, 2-2.3 $\mathrm{mm}$ de largo, epunteado, densamente ferrugíneo seríceo; corola morada, epunteada, la lámina del estandarte cóncava, suborbicular 8-9 mm de ancho, moderadamente canescente serícea. Ovario 12-ovulado. Legumbre indehiscente, anchamente elíptica a ligeramente obovada, $11-17 \mathrm{~cm}$ de largo, 4.5-5.7 $\mathrm{cm}$ de ancho, la base atenuada, el ápice cortamente rostrado, coriácea a suberosa, densamente pardo-amarillento velutino a glabrescente, el margen vexilar ligeramente sulcado, hasta $1.2 \mathrm{~mm}$ de grosor; el margen carinal angostamente aquillado; semillas 1 por fruto, ca. $14 \mathrm{~mm}$ de largo, ca. $7 \mathrm{~mm}$ de ancho, plántula hipogea, eofilos opuestos, unifoliolados.

Distribución y hábitat. Se encuentra solamente en Panamá, aunque al estar en la Sierra de Pierre en el Darien, es posible que también se localice en Colombia. En selvas altas de subcaducifolias a perennifolias. La altitud de 0-490 m. Florece a mediados de diciembre; fructifica de diciembre a abril. Los frutos se dispersan por el viento.

Paratipos: PANAMÁ. Darien: Orilla Laguna de Sta. Rita, en el camino a Boca de Cupe, al N de Cana, Sierra Pirre, en el valle al E, $7^{\circ} 45^{\prime}$ N, 77 39' O, elev. 490 m, M. Sousa 11078 y T. Robledo (MEXU). Panamá: sin datos, I. Valdespino 260, E. Rios y I. Rojas (MO).

\section{Discusión}

Especie que pertenece a la sect. Densiflori Benth. Pero que no parece estar cercanamente emparentada con ninguna de las hasta hoy conocidas, es notable por sus folíolos largamente caudado-alesnados, y su legumbre de gran tamaño y textura coriácea a subleñosa.

El epíteto de esta nueva especie se refiere a su enorme fruto.

Lonchocarpus monteviridis M. Sousa, sp. nov. Tipo: COSTA RICA. Puntarenas: Monteverde community, elev. 1500 m, W.A. Haber 322 (holotipo, MeXu; isotipo, Mo). Fig. 4. Arbor 6-20 m alta; folia 7-9-foliolata, foliolis ellipticis, sparse sericeis in superficiebus ambabus folíolorum, apice acuminatis. Inflorescentiae simplices, 7.5-24 cm longae, pedunculis floralibus tenuibus, $5-7 \mathrm{~mm}$ longis, pedicellis 3.5-4.5 mm longis; bracteolae suboppositae vel alternae, a calyce distantes, lineares, 1.1-1.3 mm longae; flores 9-11 mm longi; calyx lobatus, epunctatus; corolla epunctata, vexilli lamina suborbiculari vel oblata 9-11 mm lata. Legumen indehiscens, ellipticum vel oblongum, $5.5-13 \mathrm{~cm}$ longum, 1.7-2.2 cm latum. 


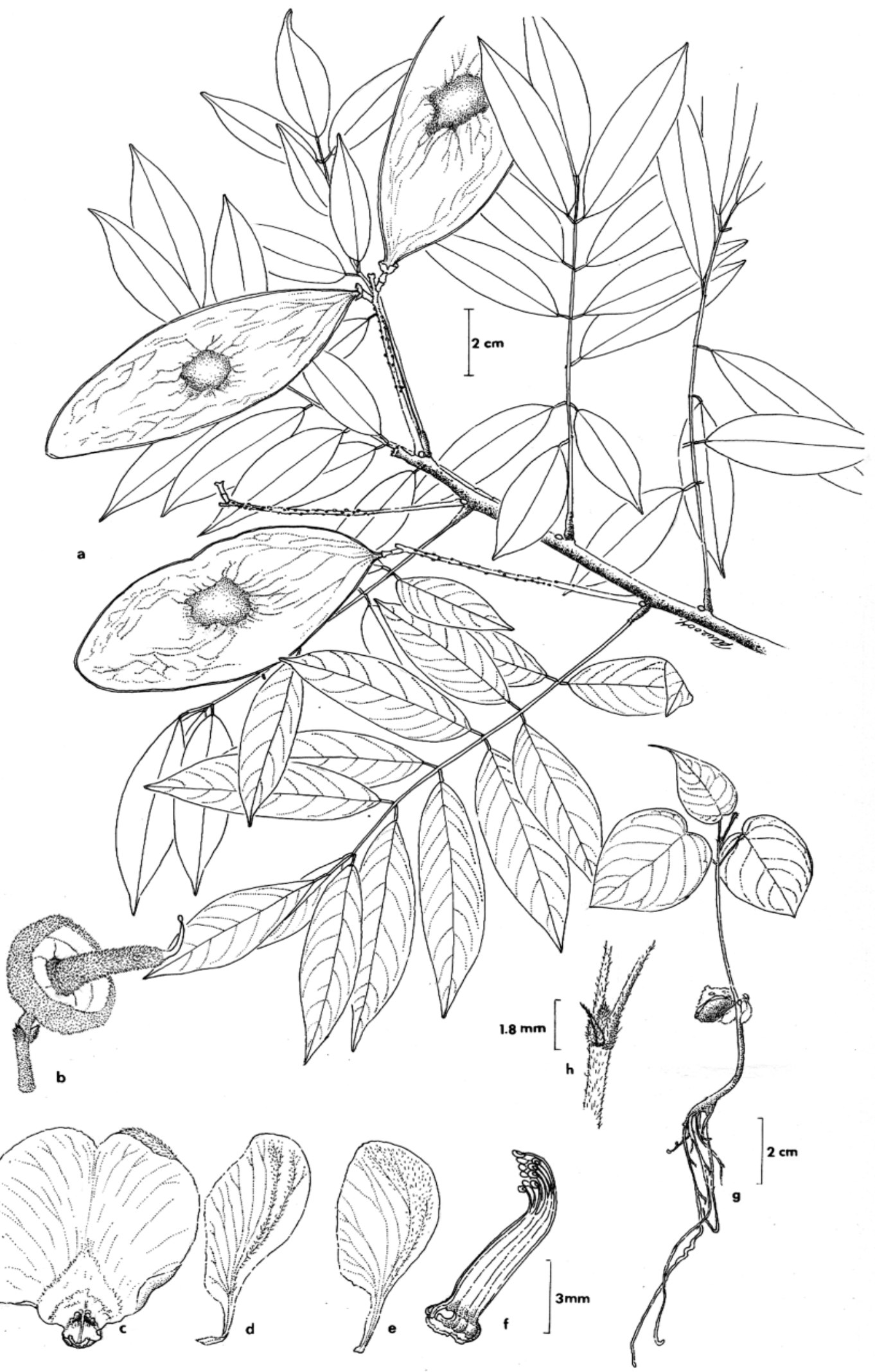

Figura 3. Lonchocarpus megacarpus M. Sousa. a, rama con frutos; b, pedicelo, bractéolas, cáliz y gineceo; c, estandarte; d, ala; e, pétalo de la quilla; f, tubo estaminal; g, plántula; h, estípula. La rama con frutos fue tomada de A. Gentry 8805, el pedicelo con el cáliz y gineceo y las partes florales de I. Valdespino et al. 260, la plántula con el detalle de la estípula de M. Sousa 11078. 


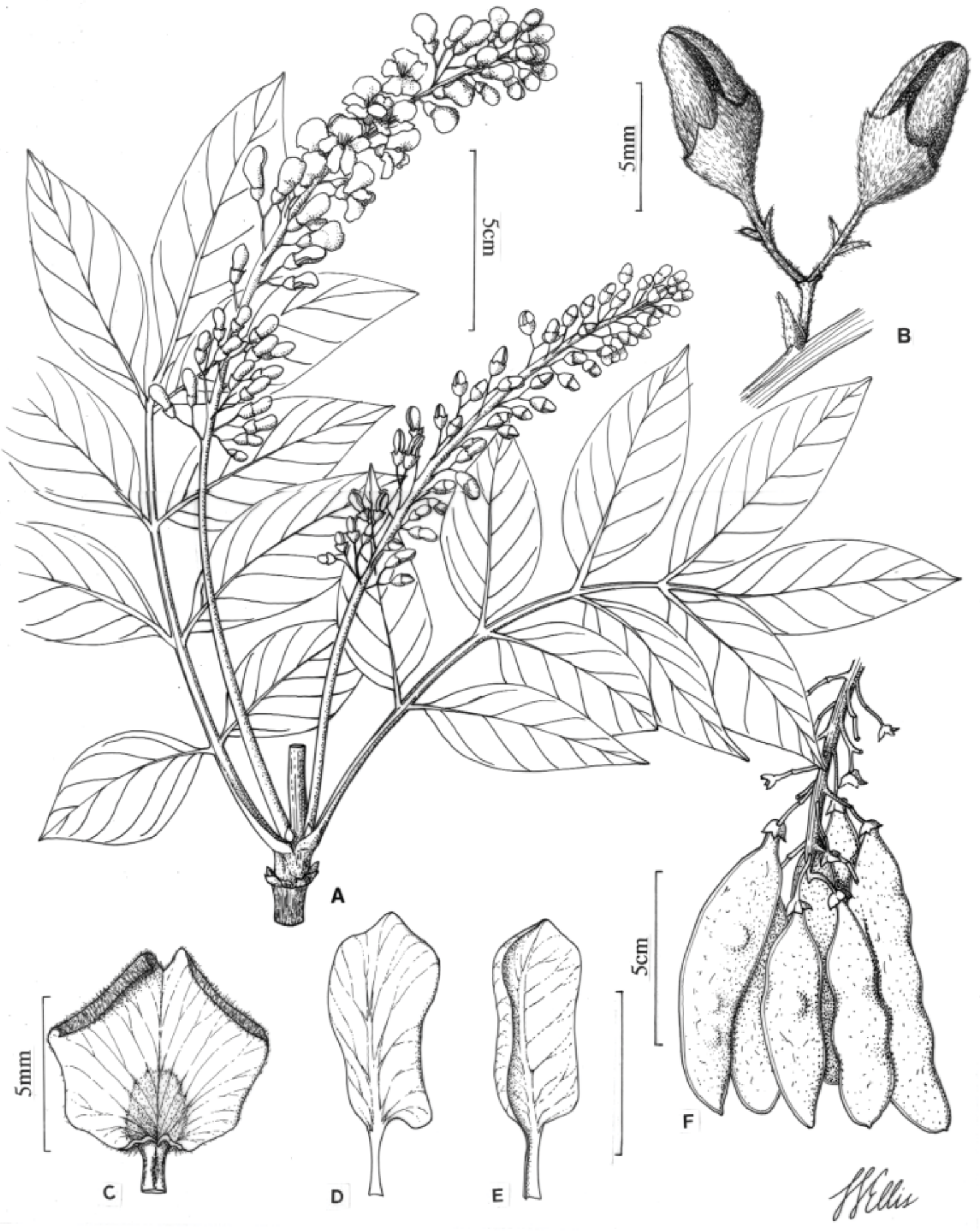

Figura 4. Lonchocarpus monteviridis M. Sousa. a, hojas e inflorescencias; b, unidad biflora, mostrando bráctea floral, pedúnculo, pedicelo, bractéolas y botones florales; c, estandarte; d, ala; e, pétalo de la quilla; f, infrutescencia. La rama con hojas, inflorescencia, unidad biflora y partes de la flor fueron tomados de W. Haber et al. 4482, y la infrutescencia de Haber y Bello 5935. 
Árboles 6-20 m de alto; corteza sin fluido resinoso al corte; ramas sólidas, cuando jóvenes moderadamente pardoamarillento velutinas, pronto glabras. Hojas 7-9-folioladas, folíolos elípticos, (3-) 5-8 (-10.5) cm de largo, (1.7-) 2-4 (-6) $\mathrm{cm}$ de ancho, cartáceos a subcoriáceos, áreas internérvias translúcidas, haz esparcidamente pardo-amarillento seríceo, pronto glabro, envés esparcidamente canescente a pardo-amarillento seríceo, el ápice acuminado, nervaduras primaria y secundarias ligeramente realzadas en el envés, nervaduras laterales 8-10; estípulas pronto caducas, no vistas. Inflorescencias simples, patentes, $7.5-24 \mathrm{~cm}$ largo, flores tienden a conglomerarse en el tercio superior, floración tardía, pedúnculos florales delgados, 5-7 $\mathrm{mm}$ de largo, bráctea subyacente, angostamente lanceolada, ca. $1.5 \mathrm{~mm}$ de largo, pedicelos 3.5-4.5 mm largo, bractéolas subopuestas a alternas, lejanas al cáliz sobre el medio al tercio superior del pedicelo, lineares, $1.1-1.3 \mathrm{~mm}$ de largo; flores $9-11 \mathrm{~mm}$ de largo; cáliz lobado, 3-3.2 cm de largo, epunteado, densamente pardo-amarillento seríceo, el lóbulo carinal 1.3-1.5 mm de largo, triangular-agudo; corola púrpura, rojizo-marrón, epunteada, la lámina del estandarte cóncava, suborbicular a oblata, 9-11 $\mathrm{mm}$ de ancho, densamente pardo-amarillento serícea. Ovario 3-4-ovulado. Legumbre indehiscente, elíptica a oblonga, $5.5-13 \mathrm{~cm}$ de largo, $1.7-2.2 \mathrm{~cm}$ de ancho, la base atenuada, el ápice ligeramente atenuado a obtuso, apiculado, subcoriácea, moderada a esparcidamente pardo-amarillento serícea, el margen vexilar angostamente alado, ala hasta $1.4 \mathrm{~mm}$ de ancho, sutura carinal angostamente aquillada; semillas 1-2 por fruto, sólo inmaduras.

\section{Nombre vulgar: "chaperno".}

Distribución y hábitat: Especie endémica de Costa Rica, de las provincias de Guanacaste y Puntarenas, muy frecuente en la Reserva de Monteverde. En bosques húmedos de baja montaña, en bosques de neblina, sobre la vertiente pacífica. La altitud a la que prospera está entre 1400 y $1560 \mathrm{~m}$. Florece de finales de abril a mediados de mayo; fructifica de finales de septiembre a finales de octubre.

Paratipos: COSTA RICA. Guanacaste. La Cruz de Abangares, elev. 1400 m, W. Haber y E. Bello C. 2879 (MEXu, MO). Puntarenas: Comunidad de Monteverde, Cordillera de Tilarán, elev. 1500-1560 m, V. J. Dryer 1346, (CR, F, Mo) Monteverde, Bull Pen, below Reserva Forestal, 10 ${ }^{\circ} 47^{\prime}$ N, 84 50'O, elev. $1500 \mathrm{~m}$, A. Gentry et al. 48784 (MEXu, MO); Monteverde, elev. $1450 \mathrm{~m}$, W. Haber 320 (CR, MEXU, мо); Monteverde, elev. 1500 m, Haber 770 (меXu, мо); Monteverde, elev. 1550 m, Haber 3105, 5935 (MEXU, MO).

\section{Discusión}

Esta especie se ubica en la sect. Densiflori Benth. sobresale por contar con pedúnculos y pedicelos muy largos y delgados y la lámina del estandarte muy ancha, este último carácter lo comparte con Lonchocarpus luteomaculatus Pittier, pero L. monteviridis tiene un fruto más largo que debe dispersarse por el viento y no por corrientes de agua. El epíteto de este binomio hace referencia a que esta especie habita fundamentalmente en la Reserva de Monteverde, Sierra de Tilarán en Costa Rica.

\section{Tipificación y caracterización de la sect. Densiflori}

De las cuatro especies de Lonchocarpus aquí descritas, tres pertenecen a la sect. Densiflori Benth. por lo que tipificamos, caracterizamos, y damos una clave para las especies de Costa Rica y Panamá.

La sect. Densiflori Benth. J. Proc. Linn. Soc. Bot. 4 (Suppl.): 85. 1860.

Lectotipo aquí designado: Lonchocarpus pentaphyllus (Poir.) DC. Prodr. 2: 259. 1825.

Dalbergia pentaphylla Poir., Lam. Encycl.Meth. Bot. (Suppl.) 2: 445. 1812. Puerto Rico: Ledrú (holotipo, P!).

Lonchocarpus latifolius D.C. Prodr. 2: 26. 1825. Puerto Rico: Bertero ex Balbis (holotipo, G; microficha I DC 358. 11: III.2!), nom. illeg.

Amerium latifolium Willd. como nombre, más no como la planta. L. Sp. Pl. ed. 4, 3: 909. 1802.

Bentham (1860) ubica en la sect. Densiflori Benth. 11 especies; de éstas se escogió como lectotipo L. latifolius [ $L$. pentaphyllus], por ser la que mejor se apega a la descripción de la sección de Bentham. Sólo Lonchocarpus latifolius [L. pentaphyllus] y $L$. macrocarpus Benth. pertenecen a esta sección, pero no se seleccionó L. macrocarpus porque sólo se conocía en fruto; en cambio, con L. latifolius [ $L$. pentaphyllus] Bentham contaba con flores y frutos; él mismo aclara darle gran peso a las características del fruto y a la vez desconocer el fruto de cinco, por lo que lo más probable es que varias no pertenezcan a este grupo.

La sect. Densiflori Benth. se caracteriza por: corteza interior sin exudado resinoso al corte; folíolos generalmente con el ápice acuminado a agudo, en ocasiones obtuso; nervaduras foliolares camptódromas; estípulas, brácteas y bractéolas lanceoladas a linear-lanceoladas u oblongas, siempre más largas que anchas; bractéolas alternas a subopuestas, patentes, generalmente distantes al cáliz, cáliz lobado; alas generalmente patentes en su extremo distal; ovario (1-) 2-4(-5)-ovulado; mecanismo floral valvar; legumbre indehiscente, el margen vexilar aquillado a alado, en ocasiones ligeramente sulcado. Plántulas con los cotiledones hipogeos, eofilos opuestos, unifoliolados. 
Clave de las especies de la sect. Densiflori para Costa Rica y Panamá:

1. Folíolos con los nervios terciarios prominentes en el envés; floración precoz a coetánea

2. Pelosidad de las partes vegetativas ferrugíneo; pecíolos y raquis profundamente canaliculados.

2. Pelosidad de las partes vegetativa canescente; pecíolos y raquis estriados

L. ferrugineus M. Sousa

3. Folíolos con la lámina redondeada a corto acuminada en el ápice; legumbres coriáceas a suberosas, 3-4 $\mathrm{cm}$ de ancho, margen vexilar con un ala angosta de 1-1.5 $\mathrm{mm}$ de ancho.

L. macrocapus Benth.

3. Folíolos con la lámina acuminada en el ápice; legumbres cartáceas a subcoriáceas, 1.5-1.8 cm de ancho, margen vexilar, con un ala angosta de menos de $1 \mathrm{~mm}$ de ancho.

L. velutinus Benth.

1.Folíolos con los nervios terciarios poco evidentes en el envés; floración tardía.

4. Legumbres con el margen vexilar aquillado, sin ala ni surcos.

5. Flores 10-12 mm de largo; legumbres orbiculares a oblongas, redondeadas o abruptamente agudas en la base y el ápice.

L. luteomaculatus Pittier

5. Flores 5-7 mm de largo; legumbres elípticas, atenuadas en la base y generalmente en el ápice.

6. Flores blancas; tallos sólidos, sin mirmecofilia. L. heptaphyllus (Poir.) DC.

6. Flores con pétalos púrpura, rosados a lila, tallos fistulosos, mirmecófilos.

7. Árboles hasta $30 \mathrm{~m}$ de alto; pedúnculos florales delgados, 2-3.5 mm de largo; legumbres de 7-19 cm largo, 3.5-5.2 cm de ancho, dispersión por aire.

\section{L. latisiliquus M. Sousa}

7. Árboles hasta $15 \mathrm{~m}$ de alto; pedúnculos florales gruesos, 0.8-1.5 mm de largo; legumbre 4.5-6.5 (-11.5) cm de largo, 1.8-2.5 cm de ancho, dispersión por agua.

4. Legumbres con el margen vexilar angostamente alado o ligeramente sulcado.

$$
\text { L. pentaphyllus (Poir.) DC. }
$$

8. Hojas 7-8-folioladas, folíolos (1.7-) 2-4(-6) cm de ancho, el ápice acuminado; inflorescencias 7.5-24 cm largo; ovario 3-4- ovulados; legumbre 1.7-2.2 cm de ancho, subcoriácea, el margen vexilar angostamente alado.

L. monteviridis M. Sousa

8. Hojas 11-13-foliolados, folíolos 1.8-2.4 cm de ancho, el ápice acuminado-alesnado; inflorescencias 6.5$8 \mathrm{~cm}$ de largo; ovario 1-2-ovulado; legumbre 4.5-5.7 cm de ancho, coriácea a suberosa, el margen vexilar ligeramente sulcado.

L. megacarpus M. Sousa

\section{Agradecimientos}

Para Fernando Chiang C. por sus comentarios y por la traducción al latín de las diagnosis; a Gloria Andrade de Sousa por mejorar el texto y escribirlo; a Elvia Esparza, Linda Ellis y Ramiro Cruz por sus excelentes láminas botánicas y a los curadores de CR, DUKE, F, MEXU, MO, NY, y P por facilitar los ejemplares para la realización de este trabajo.

\section{Literatura citada}

Sousa S., M. 1986 [1987]. Adiciones a las leguminosas de la Flora de Nicaragua. Annals of the Missouri Botanical Garden 73: 722-737.

Sousa S., M. 1992. Willardia, una nueva sección de género Lonchocarpus (Leguminosae).Anales del Instituto de Biología, Universidad Nacional Autónoma de México, Serie Botánica 63: 147-154.

Sousa S., M. 1999 [2000]. Especie nueva de Lonchocarpus (Leguminosae) de Nicaragua y Costa Rica. Anales del Instituto de Biología, Universidad Nacional Autónoma de México, Serie Botánica 70: 137-180. 